\title{
Effects of Surface Treatments and Cement Types on the Bond Strength of Porcelain-to-Porcelain Repair
}

\author{
Fatma Faiez Mohamed, BDS, MS, ${ }^{1}$ Matthew Finkelman, PhD, ${ }^{2}$ Roya Zandparsa, DDS, MSc, DMD, ${ }^{3}$ \\ Hiroshi Hirayama, DDS, DMD, MS, ${ }^{3} \&$ Gerard Kugel, DMD, MS, $\mathrm{PhD}^{3}$ \\ ${ }^{1}$ Department of Oral Health Sciences, School of Dentistry, University of Michigan, Ann Arbor, MI \\ ${ }^{2}$ Department of Public Health and Community Service, Tufts University School of Dental Medicine, Boston, MA \\ ${ }^{3}$ Department of Prosthodontics and Operative Dentistry, Tufts University School of Dental Medicine, Boston, MA
}

The article is associated with the American College of Prosthodontists' journal-based continuing education program. It is accompanied by an online continuing education activity worth 1 credit. Please visit www.wileyhealthlearning.com/jopr to complete the activity and earn credit.

\section{Keywords}

Shear bond strength; ceramic failure; composite/porcelain repair; silane coupling agent; surface treatments.

\section{Correspondence \\ Fatma Mohamed, University of Michigan - Oral Health Sciences, 1011 N. University, Ann Arbor, Ml 48109 \\ E-mail: fmohamed@umich.edu}

The authors deny any conflicts of interest

Accepted March 7, 2014

doi: 10.1111/jopr.12194

\begin{abstract}
Purpose: The purpose of this in vitro study was to evaluate the effects of four surface treatments and two resin cements on the repair bond strength of a ceramic primer. Materials and Methods: Eighty-eight pairs of disks ( 10 and $5 \mathrm{~mm}$ in diameter, $3 \mathrm{~mm}$ thickness) were prepared from heat-pressed feldspar ceramics (GC Initial IQ). After being stored in mucin-artificial saliva for 2 weeks, the 10 -mm disks were divided into four surface treatment groups $(\mathrm{n}=22)$ and then treated as follows: (1) no treatment (control); (2) 40\% phosphoric acid; (3) 5\% hydrofluoric acid + acid neutralizer $+40 \%$ phosphoric acid; (4) silica coating (CoJet-sand) $+40 \%$ phosphoric acid. The 5-mm disks were treated with $5 \%$ hydrofluoric acid $+40 \%$ phosphoric acid. The two sizes of porcelain disks, excluding the control group, were primed with Clearfil Ceramic Primer. The specimens in each group were further divided into two subgroups of 11 each, and bonded with Clearfil Esthetic Cement (CEC) or Panavia F 2.0 Cement (PFC). The specimens were stored in distilled water at $37^{\circ} \mathrm{C}$ for 24 hours, thermocycled for 3000 cycles at 5 to $55^{\circ} \mathrm{C}$, and stored at $37^{\circ} \mathrm{C}$ for an additional 7 days. Shear bond strength (SBS) was measured with a universal testing machine at a $0.5 \mathrm{~mm} / \mathrm{min}$ crosshead speed until fracture. Statistical analysis of the results was carried out with a two-way ANOVA and Tukey HSD test $(\alpha=0.05)$. Debonded specimen surfaces were examined under an optical microscope to determine the mode of failure.

Results: The statistical analysis showed that the SBS was significantly affected by surface treatment and resin cement $(p<0.05)$. For treatment groups bonded with CEC, the SBS (MPa) values were (1) $2.64 \pm 1.1$, (2) $13.31 \pm 3.6$, (3) $18.88 \pm 2.6$, (4) $14.27 \pm 2.7$, while for treatment groups cemented with PFC, the SBS (MPa) values were (1) $3.04 \pm 1.1$, (2) $16.44 \pm 3.3$, (3) $20.52 \pm 2.2$, and (4) $16.24 \pm 2.9$. All control specimens exhibited adhesive failures, while mixed types of failures were observed in phosphoric acid-treated groups. The other groups revealed mainly cohesive and mixed failures.

Conclusions: Combined surface treatment of etching with hydrofluoric acid and phosphoric acid provides the highest bond strengths to porcelain. Also, PFC exhibited higher SBS than CEC did.
\end{abstract}

Metal ceramic restorations have been widely used in dentistry for several decades ${ }^{1,2}$ due to their predictable strength and performance. ${ }^{3}$ However, failure of these restorations may occur when the veneering porcelain fractures, ${ }^{4-7}$ compromising esthetics and function. ${ }^{6}$ Previous clinical studies on metal ceramic crowns and partial fixed dental prostheses reported that fractures of veneering porcelain occur $2.38 \%$ to $8 \%$ of the time. ${ }^{8,9}$ This rate may increase even more with implantsupported metal ceramic restorations. ${ }^{10}$ Replacement of a failed restoration, without compromising the supporting structure, is difficult, and is not practical, considering replacement cost and time. ${ }^{7,11-13}$ Various clinical techniques, direct and indirect, for repairing metal ceramic restorations have been described, ${ }^{9,14-17}$ offering less expensive and conservative alternatives to direct replacement. ${ }^{9}$

The success of the repair is largely dependent on the strength and durability of the bond between a repair material and porcelain. Various surface treatments, which either mechanically 
or chemically enhance bond strength, have been proposed. Mechanical bonding can be promoted by treatments such as acid etching with hydrofluoric acid (HF), ${ }^{11,18,19}$ phosphoric acid, ${ }^{20,21}$ or with acidulated phosphate fluoride, ${ }^{22,23}$ airborneparticle abrasion with aluminum oxide ${ }^{1,24}$ or silica-coated alumina particles; $;^{2,6,25,26}$ or roughening with a diamond rotary instrument. ${ }^{20}$ In addition, chemical bonding can be achieved by a silane coupling agent. ${ }^{13,19,27-29}$ Finally, an application of a layer of glass fiber-reinforced composite resin on the surface under the repair composite resin has also been suggested. ${ }^{30}$ However, it remains uncertain as to which procedure provides the best clinical results.

Etching silica-based ceramics (i.e., feldspathic porcelain) with HF creates micromechanical undercuts on the surface. HF selectively dissolves the glass matrix of porcelain and exposes the crystalline structure, ${ }^{12,31}$ so the repair material can penetrate the undercuts and form micromechanical interlocking with the resin composite. ${ }^{32}$ However, HF is known to have hazardous effects on human tissue, ${ }^{31}$ and concerns about its use intraorally have been reported. ${ }^{1,23}$ To protect adjacent teeth and tissue, using a rubber dam and sodium bicarbonate/calcium source acid neutralizing medium is recommended. ${ }^{12}$

A chairside silica-coating technique that involves airborne particle abrasion with silica-modified $\mathrm{Al}_{2} \mathrm{O}_{3}$ particles has also been described for repair of fractured metal ceramic restorations. ${ }^{33}$ Silica-coating treatment provides ultrafine mechanical retention, as well as chemical adhesion between the composite resin and the ceramic or metal, using the silane coupling agent. ${ }^{5,26}$ Ozcan and Niedermeier ${ }^{5}$ showed that intraoral silica coating of 289 fractured metal ceramic restorations, using the CoJet system, resulted in an $89 \%$ success rate after 3 years.

Composite resins used in repair have also been shown to affect bond strength. ${ }^{29,34}$ It has been reported that large particlesize composites or hybrid type resins at the porcelain interface result in higher bond strengths than small particle-size composites, ${ }^{35}$ and that resin cement containing filler demonstrates better mechanical properties than resin cement without fillers. ${ }^{36}$ Matsumura et $\mathrm{al}^{37}$ reported that dual-cure cement exhibited greater bond strength than chemically activated cement, but also stated that this difference could be due to the presence of an adhesive monomer (MDP) in only one of the two cements, rather than the mode of activation. MDP is a dual-functional phosphate monomer, referring to 10-methacryloyloxydecyl dihydrogen phosphate monomer. The effect of resin cements on bond strength, depending on the absence or presence of MDP, is less certain.

With the introduction of silanes in the early $1960 \mathrm{~s},{ }^{38}$ chemical adhesion between resin composite and porcelain could be achieved. The silane coupling agent $\gamma$-methacryloxypropyl trimethoxysilane is a bi-functional molecule consisting of a silanol group that reacts with $(-\mathrm{OH})$ groups on the porcelain surface, and a methacrylate group that copolymerizes with the resin matrix of the composite, forming siloxane bonds. It also enhances the resin bond by improving wettability of the ceramic surface. ${ }^{28}$ The silane coupling agent, which is included in several repair systems, showed enhanced repair bond strength of porcelain. ${ }^{12,19,27,29}$ Many efforts have been made to improve the effectiveness of silanes by using either heat treatment, through warm-air drying, ${ }^{28}$ carbon dioxide laser irradiation, ${ }^{39}$ or by acid catalysis. ${ }^{28}$ Some silane coupling agents were effective after acid etching with phosphoric acid. ${ }^{36,40}$

A single-step silane primer, Clearfil Ceramic Primer (Kuraray Medical, Okayama, Japan), indicated for ceramic repair, has been developed. There is little information concerning its bond strength to porcelain. This primer contains the silane coupling agent and the adhesive monomer MDP in ethanol solvent. The aim of this in vitro study was to evaluate effects of four surface treatments and two dual-cure resin cements on the repair bond strength of the silane primer to porcelain.

\section{Materials and methods}

Information on the materials used in this study is summarized in Table 1. Feldspathic porcelain (GC Initial IQ - One-Body, Press-over-Metal) indicated for metal ceramic restorations was used as a substrate material. Eighty-eight pairs of porcelain disks were fabricated using a heat-pressing technique. Two sizes of porcelain disks were made from wax patterns approximately 10 and $5 \mathrm{~mm}$ in diameter ( $3.5 \mathrm{~mm}$ thickness). The patterns were sprued, invested, and heat pressed according to the manufacturer's instructions. Following the heat-pressing procedure, investment disks were bench cooled and divested by airborne-particle abrasion with $50-\mu \mathrm{m}$ aluminum oxide at 2-bar pressure, and the attached sprue was carefully cut.

\section{Surface preparation of 10-mm diameter disks}

To simulate exposure to the oral environment after porcelain fracture, the 10-mm disks were stored in artificial saliva (Mouth Kote; Parnell Pharmaceuticals, Inc., San Rafael, CA) for 2 weeks. Next, each disk was inserted in a ring with poly(methyl methacrylate) resin (Dentsply Caulk, Milford, DE), ensuring that the bonding surface was left uncovered. Then, each disk's bonding surface was roughened sequentially under running water with 240-, 320-, and 600-grit abrasive papers (Buehler, Ltd., Lake Bluff, IL). No ultrasonic cleaning was done because this would be clinically impossible during an intraoral repair. The disks were divided equally into four groups $(n=22)$, each receiving one of the four treatments as follows:

Group 1: No further treatment after grinding with abrasive papers (Control).

Group 2: Etching with $40 \%$ phosphoric acid gel (K-Etchant; Kuraray Medical, Inc.) for 5 seconds, then washed, and dried.

Group 3: Etching with $<5 \%$ HF gel (IPS Ceramic Etching Gel; Ivoclar Vivadent AG, Schaan Liechtenstein) for $60 \mathrm{sec}-$ onds. An acid neutralizer agent (EtchArrest; Ultradent Products, Inc., South Jordan, UT) was then applied and left for 60 seconds until the color of the etchant was no longer visible. Next, bonding surfaces were rinsed with water and dried. Finally, the surfaces were treated with $40 \%$ phosphoric acid gel (Kuraray Medical) for 5 seconds, and then washed, and dried.

Group 4: Airborne abrasion was performed using an intraoral sandblaster (Microetcher II; Danville Engineering, Inc., San Ramon, CA) filled with $30-\mu \mathrm{m} \mathrm{Al}_{2} \mathrm{O}_{3}$ silicated particles (CoJet sand; 3M ESPE, Seefeld, Germany). The abrasive was blasted perpendicular to the surface at a pressure of $45 \mathrm{psi}$, at a distance of $10 \mathrm{~mm}$ for approximately 15 seconds, $40 \%$ phosphoric acid 
Table 1 Materials used

\begin{tabular}{|c|c|c|c|c|}
\hline Materials & Manufacturer & Type & Lot number & Composition \\
\hline $\begin{array}{l}\text { GC Initial IQ - One-Body, } \\
\text { Press-over-Metal }\end{array}$ & $\begin{array}{l}\text { GC America, Inc., Alsip, } \\
\text { IL }\end{array}$ & Feldspathic porcelain & 200801211 & Shade A2 \\
\hline Clearfil Ceramic Primer & $\begin{array}{l}\text { Kuraray Medical, } \\
\text { Okayama, Japan }\end{array}$ & Saline coupling agent & 00009B & $\gamma$-MPS, MDP, $80 \%$ ethanol \\
\hline Clearfil Esthetic Cement & Kuraray Medical & Dual-cure cement & 16AAA & $\begin{array}{l}\text { Bis-GMA, TEGDMA, aromatic and } \\
\text { aliphatic dimethacrylates, } \\
\text { colloidal silica, benzoyl peroxide, } \\
\text { accelerator, dl-camphorquinone, } \\
\text { filler } 49 \text { vol\% (70 wt\%) }\end{array}$ \\
\hline Panavia F 2.0 Cement & Kuraray Medical & Dual-cure cement & $\begin{array}{l}\text { Paste A: 00391A } \\
\text { Paste B: 00204A }\end{array}$ & $\begin{array}{l}\text { MDP, aromatic and aliphatic } \\
\text { dimethacrylates, catalysts, } \\
\text { accelerator, dl-camphorquinone } \\
\text { filler } 59 \text { vol\% (78 wt\%) }\end{array}$ \\
\hline K-Etchant Gel & Kuraray Medical & Etchant & 00444A & $\begin{array}{l}40 \% \text { phosphoric acid gel, colloidal } \\
\text { silica, water, dyes }\end{array}$ \\
\hline ED Primer II & Kuraray Medical & Self-etch primer & $\begin{array}{l}\text { Liquid A: 00273B } \\
\text { Liquid B: 00148B }\end{array}$ & $\begin{array}{l}\text { MDP, 5-NMSA (salicylic acid } \\
\text { monomer), HEMA, water and } \\
\text { accelerators }\end{array}$ \\
\hline Oxyguard II & Kuraray Medical & Oxygen-blocking gel & 00607A & $\begin{array}{l}\text { Mixture of glycerol and } \\
\text { polyethylene glycol }\end{array}$ \\
\hline IPS Ceramic Etching Gel & $\begin{array}{l}\text { Ivoclar Vivadent AG, } \\
\text { Schaan Liechtenstein }\end{array}$ & Etchant & M55091 & $<5 \%$ Hydrofluoric acid \\
\hline EtchArrest & $\begin{array}{l}\text { Ultradent Products Inc., } \\
\text { South Jordan, UT }\end{array}$ & Acid neutralizer & & $\begin{array}{l}\text { Calcium carbonate and Sodium } \\
\text { bicarbonate }\end{array}$ \\
\hline CoJet sand & $\begin{array}{l}\text { 3M ESPE, Seefeld, } \\
\text { Germany }\end{array}$ & Silica coating & 370113 & $\begin{array}{l}30 \mu \mathrm{m} \mathrm{Al} \mathrm{A}_{3} \text { particles modified by } \\
\text { silica }\end{array}$ \\
\hline Mouth Kote & $\begin{array}{l}\text { Parnell Pharmaceuticals, } \\
\text { San Rafael, CA }\end{array}$ & Artificial saliva & 4938963 & $\begin{array}{l}\text { Water, xylitol, sorbitol, Yerba Santa, } \\
\text { citric acid, natural lemon-lime } \\
\text { flavor, ascorbic acid, sodium } \\
\text { benzoate, sodium saccharin }\end{array}$ \\
\hline
\end{tabular}

$\gamma$-MPS, $\gamma$-methacryloxypropyl-trimethoxy silanes; MDP, 10-methacryloyloxydecyl dihydrogen phosphate; 5-NMSA: N-methacryloyl-5-aminosalicylic acid; HEMA, 2-hydroxyethylmethacrylate; Bis-GMA, Bisphenol A diglycidylmethacrylate; TEGDMA: Triethylene glycol dimethacrylate.

(Kuraray Medical) was applied for 5 seconds, and then washed and dried.

A piece of adhesive transparent tape (Scotch; 3M, St. Paul, $\mathrm{MN}$ ) with a thickness of $0.50 \mu \mathrm{m}$ and a circular hole $3 \mathrm{~mm}$ in diameter was positioned on the surface of the 10 -mm diameter disks, to control the area of the bonding as well as the cement thickness.

\section{Surface treatment of 5-mm diameter disks}

The bonding surfaces of 5-mm disks were first wet roughened with 240-, 320-, and 600-grit abrasive papers for surface standardization. Then they were etched with $<5 \%$ HF gel (Ivoclar Vivadent) for 60 seconds, washed and dried, and then ultrasonically cleaned in $99.5 \%$ ethanol for 5 minutes. Treating the bonding surface with HF is a common procedure in dental labs when preparing porcelain veneers for bonding. ${ }^{31}$ The following day, the bonding surface was treated with $40 \%$ phosphoric acid (Kuraray Medical) for 5 seconds, to activate the porcelain surface before application of the silane coupling agent.

\section{Priming and luting}

Two sizes of porcelain disks were treated with the silane primer (Clearfil Ceramic Primer), and dried by blowing mild oil-free air for 10 seconds to evaporate the solvent. The disks in the control group were neither treated with the primer, nor were their corresponding 5-mm disks. The disks were then cemented with one of two dual-cure resin luting cements: Clearfil Esthetic Cement, or Panavia F 2.0 Cement (Kuraray Medical).

Because Panavia F 2.0 cement does not chemically polymerize by itself, applying an additional primer, ED Primer II (Kuraray Medical), is required before the cement. ED Primer II A \& B were mixed and applied on top of the ceramic primer on 5-mm disks, and dried with blown air. After cementation, a constant load of $750 \mathrm{~g}$ was applied to the specimens to standardize the exerted pressure as well as the cement thickness. Excess marginal cement was removed before complete hardening of the cement. When Panavia F 2.0 cement was used, an oxygen-blocking gel (Oxyguard II, Kuraray Medical) was applied around the interface for 3 minutes, to allow the cement to be chemically polymerized. After bonding, the luting cements were polymerized with a visible blue light curing unit (Halogen 
Table 2 Abbreviation of comparison groups

\begin{tabular}{lcc}
\hline & $\begin{array}{c}\text { Clearfil Esthetic } \\
\text { Cement (CEC) }\end{array}$ & $\begin{array}{c}\text { Panavia F 2.0 } \\
\text { Cement (PFC) }\end{array}$ \\
\hline Control (CT) & CT-CEC & CT-PFC \\
$\begin{array}{l}\text { Phosphoric acid (P) } \\
\text { Hydrofluoric acid and } \\
\text { phosphoric acid (HP) }\end{array}$ & P-CEC & P-PFC \\
$\begin{array}{c}\text { Silica coating and } \\
\text { phosphoric acid (SIP) }\end{array}$ & HP-CEC & \\
& SIP-CEC & SIP-PFC
\end{tabular}

Curing Light, Elipar 2500, 3M ESPE), at an intensity of 400 to $500 \mathrm{~nm}$ for four 20 -second intervals, spaced equally around circumference of the luted disks. The total curing time was 80 seconds for each assembly. Eighty-eight specimens were made, 11 specimens in each group for a total of eight groups. Table 2 explains all comparison groups and their abbreviations. The specimens were stored in $37^{\circ} \mathrm{C}$ distilled water for 24 hours, subsequently thermocycled between $5^{\circ} \mathrm{C}$ and $55^{\circ} \mathrm{C}$ for $3000 \mathrm{cy}-$ cles with a 30-second dwell time in each bath (Model: GP-200; Thermo NESLAB, Newington, NH), and then stored in $37^{\circ} \mathrm{C}$ distilled water for an additional 7 days before being subjected to a shear test.

\section{Shear testing}

The shear bond strengths (SBS) of the specimens were measured using a universal testing machine (Instron Co., Model 5566A, Norwood, MA). Each specimen was mounted in a fixture on the testing machine. A shear load was applied with a semicircular device with an internal diameter of $5 \mathrm{~mm}$ corresponding to the diameter of 5-mm disks, and positioned as close to the interface as possible. The load was applied at a $0.5 \mathrm{~mm} / \mathrm{min}$ crosshead speed until failure. The debonding surfaces were examined under a light microscope with original $10 \times$ power magnification to determine the mode of failure. Three types of failures were recorded as: (1) adhesive failure at the porcelain/resin cement interface, (2) cohesive failure within porcelain or resin cement, and (3) combination of adhesive and cohesive failures or a mixed failure. ${ }^{2,6}$

\section{Power calculation}

A power calculation was conducted using nQuery Advisor (Version 7.0). Assuming a variance in means of 7.4 MPa for the surface treatments, as well as a standard deviation of 3.0, a sample size of $\mathrm{n}=11$ per group was adequate to obtain a Type I error rate of $5 \%$ and a power greater than $90 \%$.

\section{Statistical analysis}

The statistical analysis was performed using a two-way ANOVA with the value of statistical significance set at the 0.05 level. The bond strength results were then submitted to a post hoc analysis (Tukey HSD) for multiple comparisons among means. The assumption of normality was verified via a quantile-quantile plot.
Table 3 Results of two-way ANOVA with independent variables of surface treatment and resin cement and bond strength as dependent variable

\begin{tabular}{lrrrrr}
\hline Source & $\begin{array}{r}\text { Sum of } \\
\text { squares }\end{array}$ & df & $\begin{array}{c}\text { Mean } \\
\text { square }\end{array}$ & \multicolumn{1}{c}{$F$} & \multicolumn{1}{c}{$p$} \\
\hline Corrected model & 3536.0 & 7 & 505.1 & 74.3 & $<0.001$ \\
Intercept & 15268.2 & 1 & 15268.2 & 2248.5 & $<0.001$ \\
Surface treatment & 3445.1 & 3 & 1148.3 & 169.1 & $<0.001$ \\
Resin cement & 70.2 & 1 & 70.2 & 10.3 & 0.002 \\
Surface treatment * & 20.6 & 3 & 6.8 & 1.0 & 0.391 \\
$\quad$ resin cement & & & & & \\
Error & 543.2 & 80 & 6.7 & & \\
Total & 19347.5 & 88 & & & \\
Corrected total & 4079.3 & 87 & & & \\
\hline
\end{tabular}

Table 4 Mean shear bond strengths, standard deviations, minimum and maximum values in each group

\begin{tabular}{lrrrr}
\hline $\begin{array}{l}\text { Combination } \\
\text { surface treatment- } \\
\text { resin cement }\end{array}$ & $\begin{array}{c}\text { Mean } \\
(\mathrm{MPa})^{*}\end{array}$ & $\begin{array}{c}\text { Standard } \\
\text { deviation } \\
\text { (SD) }\end{array}$ & $\begin{array}{c}\text { Minimum } \\
\text { (MPa) }\end{array}$ & $\begin{array}{r}\text { Maximum } \\
\text { (MPa) }\end{array}$ \\
\hline CT-CEC & 2.64 & 1.07 & 1.78 & 5.40 \\
P-CEC & 13.31 & 3.61 & 9.46 & 20.51 \\
HP-CEC & 18.88 & 2.63 & 15.05 & 23.98 \\
SIP-CEC & 14.27 & 2.72 & 11.12 & 20.04 \\
CT-PFC & 3.04 & 1.09 & 1.61 & 5.05 \\
P-PFC & 16.44 & 3.31 & 9.55 & 21.11 \\
HP-PFC & 20.52 & 2.21 & 17.32 & 24.04 \\
SIP-PFC & 16.24 & 2.94 & 11.28 & 20.99 \\
\hline
\end{tabular}

*p-values of post hoc tests for surface treatment (Tukey's HSD):

CT vs. P: $p<0.001$

CT vs. HP: $p<0.001$

CT vs. SIP: $p<0.001$

P vs. HP: $p<0.001$

P vs. SIP: $p=0.963$

HP vs. SIP: $p<0.001$.

\section{Results}

The results of this investigation revealed that SBS was significantly affected by the surface treatment $(p<0.001)$ and type of resin cement ( $p=0.002$; Table 3 ). Further analysis with Tukey HSD test revealed that the group etched with both HF and phosphoric acid gave significantly higher $(p<0.001)$ bond strength compared to other surface treatments or no treatment (control). No significant differences $(p=0.963)$ could be detected between silica coating-treated group and that treated with phosphoric acid only. For all groups, the strength values obtained for Panavia F 2.0 cement were higher than those obtained for Clearfil Esthetic Cement (Table 4).

The control group resulted in very low SBS (Table 4). Without silane, the control group cemented with Panavia F 2.0 had a higher mean bond strength than the one bonded with Clearfil Esthetic Cement; however, there is no substantial difference. Failure mode analysis of control groups revealed $100 \%$ adhesive failures at the interface in all control specimens (Table 5). 
Table 5 Number and incidence (\%) of failure type in each group

\begin{tabular}{lcccc}
\hline $\begin{array}{l}\text { Surface } \\
\text { treatment- } \\
\text { resin cement }\end{array}$ & $\begin{array}{c}\text { Adhesive } \\
\text { failure }\end{array}$ & $\begin{array}{c}\text { Cohesive } \\
\text { failure }\end{array}$ & $\begin{array}{l}\text { Mixed } \\
\text { failure }\end{array}$ & Total \\
\hline CT-CEC & $11(100 \%)$ & & & 11 \\
P-CEC & $3(27.3 \%)$ & $5(45.5 \%)$ & $3(27.3 \%)$ & 11 \\
HP-CEC & & $11(100 \%)$ & & 11 \\
SIP-CEC & $11(100 \%)$ & $6(54.5 \%)$ & $5(45.5 \%)$ & 11 \\
CT-PFC & $3(27.3 \%)$ & $4(36.4 \%)$ & $4(36.4 \%)$ & 11 \\
P-PFC & & $11(100 \%)$ & & 11 \\
HP-PFC & $7(63.6 \%)$ & $4(36.4 \%)$ & 11 \\
SIP-PFC & $28(31.8 \%)$ & $44(50 \%)$ & $16(18.1 \%)$ & 88 \\
Total & & & &
\end{tabular}

Adhesive failure at the porcelain/resin cement interface; cohesive failure within porcelain or resin cement; and combination of adhesive and cohesive failures or mixed failure.

The mean shear bond strengths for groups that received only phosphoric acid treatment were $13.31 \pm 3.61$ and $16.44 \pm$ 3.31 MPa for Clearfil Esthetic Cement and Panavia F 2.0 Cement, respectively, a highly statistically significance different $(p<0.001)$ from the control group. A combination of modes of failures, adhesive, cohesive and mixed, was observed in these phosphoric acid groups (Table 5).

The greatest mean bond strength of $20.52 \pm 2.21 \mathrm{MPa}$ was obtained when HF and phosphoric acid treatment was used in conjunction with Panavia F 2.0 cement (HP-PFC). Failure sites revealed $100 \%$ cohesive fractures in porcelain of $10-\mathrm{mm}$ disks (Table 5).

Silica coating and subsequent conditioning with phosphoric acid provided mean bond strengths of $14.27 \pm 2.72$ and 16.24 $\pm 2.94 \mathrm{MPa}$ for the Clearfil Esthetic Cement and Panavia F 2.0 Cement, respectively, and showed cohesive and mixed failures (Table 5). Notably, the modes of porcelain failure are consistent with bond strength results in each group.

The light microscopic examination (original magnification $10 \times)$ of treated surfaces performed immediately after surface treatments showed no difference between the control (no treatment) and phosphoric acid-treated surfaces. Both showed clean surfaces with some scratches that probably resulted from roughening with abrasive papers (Fig 1A, B). Microscopic purple deposits scattered among the whitish remnants were seen after etching with $\mathrm{HF}$ and neutralization with EtchArrest (Fig 1C). Silica-coated porcelain surfaces exhibited a misty appearance, which may be caused by silica layering (Fig 1D).

\section{Discussion}

This in vitro study was conducted to investigate the influence of four surface treatments and two dual-cure resin cements on the repair bond strength of the ceramic primer. The results indicated that surface treatments improved the SBS of the ceramic primer. Treating porcelain surfaces with $\mathrm{HF}$ followed by phosphoric acid exhibited the highest bond strength. The high bond strength resulting from the use of $\mathrm{HF}$, alone or combined with other surface treatments, was confirmed in other studies. . $^{11,12,18,19,27} \mathrm{HF}$ acid etching is known to increase total surface area and surface energy, as well as improve the wettability of the porcelain surface. ${ }^{32}$ In this study, etching with $\mathrm{HF}$ and neutralization with a sodium bicarbonate-based agent (EtchArrest) revealed microscopic whitish and purple precipitates formed on the bonding surfaces. Canay et $\mathrm{al}^{22}$ observed that the white precipitates were fluorosilicate precipitates of $\mathrm{Na}, \mathrm{K}, \mathrm{Ca}$, and $\mathrm{Al}$ created on the glass-ceramic surface after etching with $\mathrm{HF}$.

A similar observation was made by Magne and Cascione, who also demonstrated that these deposits could be partly removed with phosphoric acid. ${ }^{41}$ The purple deposits (Fig 1C) may result from the reaction between HF and the sodium bicarbonate contained in the neutralizing agent $\left(\mathrm{NaHCO}_{3}+\mathrm{HF}\right.$ $\left.\Leftrightarrow \mathrm{NaF}+<\mathrm{H}_{2} \mathrm{CO}_{3}>\right),{ }^{42}$ or could be remnants of neutralizing medium (EtchArrest), considering the color of the medium used in this study is purple. The HF deposit neutralization has been shown to reduce the bond strength between dentin and glass-ceramic. ${ }^{42}$ Further investigation is needed as to whether the use of the neutralizing agent affects the repair bond strength of the ceramic primer.

Previous studies have demonstrated that silica coating and HF treatments were equally effective in improving the bond strength between porcelain and composite resin. ${ }^{25,26}$ However, the results of this study showed that HF followed by phosphoric acid treatment showed higher bond strengths than those treated with silica coating and phosphoric acid. It is possible that the phosphoric acid destroyed the silica layer or removed it when it was applied to the surface pretreated with silica particles, compromising the chemical bonding that should occur between the silica particles and the silane coupling agent. ${ }^{6}$ However, whether using phosphoric acid following silica coating affects bond strength is less certain, and further investigation is needed.

In this study, phosphoric acid treatment did not exhibit an evident etching effect. Although previous studies showed that alterations in surface topography by phosphoric acid were unclear, ${ }^{27,40,43}$ improvement in bond strength was observed. ${ }^{36}$ Phosphoric acid treatment probably enhances chemical bonding but not mechanical bonding, as it enhances the chemical activity of the silane coupling agent, ${ }^{43}$ and that without silane, phosphoric acid treatment produced very low-strength bonds. ${ }^{27,44}$ Shimada et al ${ }^{40}$ showed that when the ceramic surfaces were treated with phosphoric acid for 5 seconds, the bond strength was very low, but when silane coupling agent was applied subsequently, a significant increase in the bond strength was observed. Additionally, other studies demonstrated that silanization dramatically increased bond strength after treatment with phosphoric acid. ${ }^{36,43,45}$ Phosphoric acid can lower ceramic surface $\mathrm{pH}$, and increase the concentration of $\mathrm{H}^{+}$, which in turn can activate silane coupling agent. ${ }^{45}$

Regardless of surface treatments, this study showed that the groups bonded with the Panavia F 2.0 cement produced greater bond strengths than those bonded with the Clearfil Esthetic Cement. This difference is probably derived from the fact that Panavia F 2.0 resin cement contains the MDP monomer. MDP is an acidic functional monomer introduced to reinforce the chemical bond between composite resin and ceramics. The silane coupling agent is rapidly hydrolyzed into silanol groups $(\mathrm{Si}-\mathrm{OH})$ in the presence of an acid. Then the silanol groups bond with silica to form siloxane bonds. The acidity of the monomer 

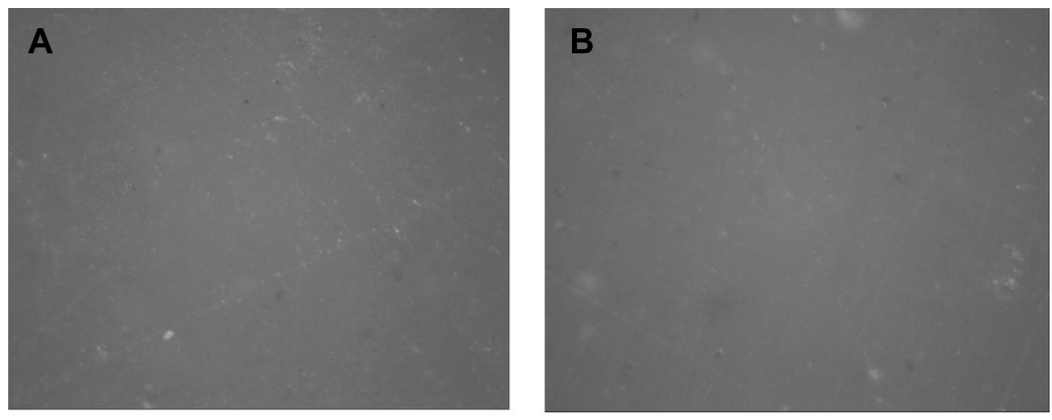

Figure 1 (A) Light microscopic examination (10x) shows porcelain surface received no treatment (control). (B) Light microscopic examination (10x) shows surface treated with phosphoric acid for 5 seconds. (C) Light microscopic examination $(10 x)$ shows microscopic white (arrow) and purple (arrowhead) deposits on porcelain surface after treatments with hydrofluoric acid and an acid neutralizer. (D) Light microscopic examination $(10 x)$ shows porcelain surface coated with CoJet-sand.
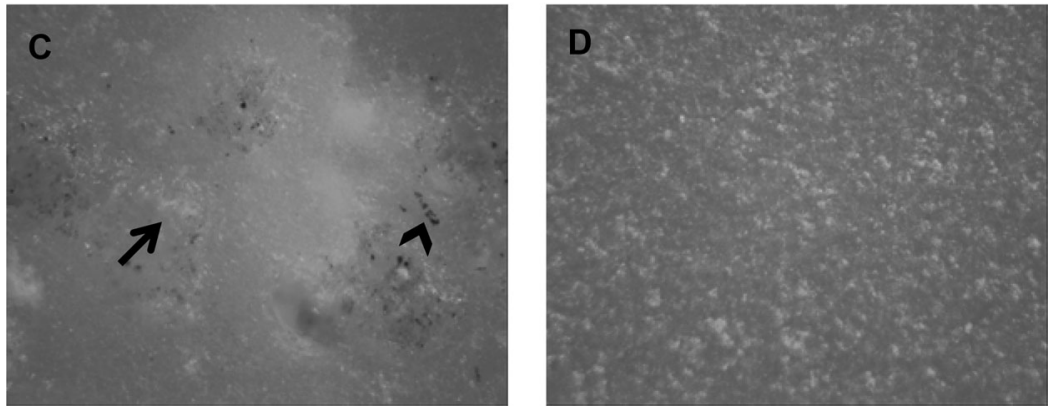

possibly promoted the formation of the siloxane bonds between the silane coupling agent and ceramic surface, ${ }^{40}$ providing high bond strength values for Panavia F 2.0 cement. Also, ED Primer II is an acidic solution ( $\mathrm{pH}$ 2.4) containing MDP. The presence of MDP in both Panavia cement and ED Primer II possibly doubled the chemical reaction and synergistically enhanced the bond to porcelain.

The importance of the silane bond for adhesion of composite resin to porcelain is well known. ${ }^{18,19,27,28}$ The bond occurs via a condensation reaction between the silanol group ( $\mathrm{Si}-\mathrm{OH})$ of the porcelain surface and the silanol group of the hydrolyzed silane molecule, creating a siloxane bond ( $\mathrm{Si}-\mathrm{O}-\mathrm{Si}$ ). The monomeric ends of silane then react with methacrylate groups of the resin material. $^{42}$

As in the clinical situation, exposure to saliva before the repair procedure was considered in this study. Previous studies have shown that salivary exposure can deteriorate bonds at resin/porcelain interfaces, ${ }^{46,47}$ and cause a significant reduction in porcelain strength. ${ }^{48}$ In this study, the saliva storage in the artificial saliva (Mouth Kote) for 14 days might influence the porcelain substrate strength. The artificial saliva contained acetic acid and ascorbic acid, and this could create pores or channels within the glassy matrix, resulting in increased diffusion of saliva and the development of internal areas of localized Si-O-Si bond breakage. ${ }^{49}$

Before repair procedures, clinicians should identify and remove the cause(s) of ceramic failures, such as bruxism and improper occlusal design. Also, choosing the appropriate surface treatment and cement type is critical to optimize the bond strength. The results of this study showed a combination of HF followed by phosphoric acid and luting with Panavia F 2.0 cement gave the highest repair bond strength. These results were based on the use of a single ceramic primer, and cannot be generalized to other primers. The repair bond strength of metal ceramic restorations has been reported in the range of 6 to $35 \mathrm{MPa} .^{2,4,6}$ The minimal SBS recommended for clinically successful performance is $13 \mathrm{MPa}$.

Porcelain-to-porcelain repair was used in this study to reflect an indirect technique, which involves preparing a piece of porcelain veneer that represents the fracture area in the laboratory, and then bonding porcelain veneer to the fractured porcelain restoration. This method is more expensive and requires more chair time, compared to a direct repair with composite resin. For instance, both porcelain surfaces need to be prepared and treated with phosphoric acid to activate the bonding surface before application of repair primer.

Shear test was used in this study because it is the most common technique reported in literature; however, it has limitations compared to microtensile and microshear bond strength tests. Shear test has been criticized for non-uniform stress distribution due to high tensile stress developed within the porcelain close to where the shear force is applied, causing cohesive fractures within the porcelain rather than at the adherent interface.

\section{Conclusions}

Under the present experimental conditions, the following conclusions were drawn:

1. Combined surface treatment of etching with hydrofluoric acid and phosphoric acid provided the highest repair bond strengths to porcelain, compared with other surface treatments.

2. Panavia F 2.0 cement provided higher bond strength values than Clearfil Esthetic cement.

3. There is no significant difference between the silica coating-treated group and that treated with phosphoric acid only. 


\section{Acknowledgments}

Many thanks are due to the manufacturing companies Kuraray America, Inc; Ultradent Products Inc; 3M; Ivoclar-Vivadent and GC America, Inc. for their generous provision and donation of the materials. This is really appreciated.

\section{References}

1. Chung $\mathrm{KH}$, Hwang YC: Bonding strengths of porcelain repair systems with various surface treatments. J Prosthet Dent 1997;78:267-274

2. Haselton DR, Diaz-Arnold AM, Dunne JT Jr: Shear bond strength of 2 intraoral porcelain repair systems to porcelain or metal substrates. J Prosthet Dent 2001;86:526-531

3. Pjetursson BE, Sailer I, Zwahlen M, et al: A systematic review of the survival and complication rates of all-ceramic and metal-ceramic reconstructions after an observation period of at least 3 years. Part I: single crowns. Clin Oral Implants Res 2007;18:73-85. Review

4. Tulunoglu IF, Beydemir B: Resin shear bond strength to porcelain and a base metal alloy using two polymerization schemes. J Prosthet Dent 2000;83:181-186

5. Ozcan M, Niedermeier W: Clinical study on the reasons for and location of failures of metal-ceramic restorations and survival of repairs. Int J Prosthodont 2002;15:299-302

6. Dos Santos JG, Fonseca RG, Adabo GL, et al: Shear bond strength of metal-ceramic repair systems. J Prosthet Dent 2006;96:165-173.

7. Güler AU, Yilmaz F, Ural C, et al: Evaluation of 24-hour shear bond strength of resin composite to porcelain according to surface treatment. Int J Prosthodont 2005;18:156-160

8. Libby G, Arcuri MR, LaVelle WE, et al: Longevity of fixed partial dentures. J Prosthet Dent 1997;78:127-131

9. Galiatsatos AA: An indirect repair technique for fractured metal-ceramic restorations: a clinical report. J Prosthet Dent 2005;93:321-323

10. Kinsel RP, Lin D: Retrospective analysis of porcelain failures of metal ceramic crowns and fixed partial dentures supported by 729 implants in 152 patients: patient-specific and implant-specific predictors of ceramic failure. J Prosthet Dent 2009;101:388-394

11. Thurmond JW, Barkmeier WW, Wilwerding TM: Effect of porcelain surface treatments on bond strengths of composite resin bonded to porcelain. J Prosthet Dent 1994;72:355-359

12. Panah FG, Rezai SM, Ahmadian L: The influence of ceramic surface treatments on the micro-shear bond strength of composite resin to IPS Empress 2. J Prosthodont 2008;17:409-414

13. Ozcan M: Fracture reasons in ceramic-fused-to-metal restorations. J Oral Rehabil 2003;30:265-269. Review

14. Latta MA, Barkmeier WW: Approaches for intraoral repair of ceramic restorations. Compend Contin Educ Dent 2000;21:635-639

15. Burke FJ, Grey NJ: Repair of fractured porcelain units: alternative approaches. Br Dent J 1994;176:251-256

16. Berksun S, Kedici PS, Saglam S: Repair of fractured porcelain restorations with composite bonded porcelain laminate contours. J Prosthet Dent 1993;69:457-458

17. Dent RJ: Repair of porcelain-fused-to-metal restorations. J Prosthet Dent 1979;41:661-664

18. Shahverdi S, Canay S, Sahin E, et al: Effects of different surface treatment methods on the bond strength of composite resin to porcelain. J Oral Rehabil 1998;25:699-705
19. Kupiec KA, Wuertz KM, Barkmeier WW, et al: Evaluation of porcelain surface treatments and agents for composite-to-porcelain repair. J Prosthet Dent 1996;76:119-124

20. Kussano CM, Bonfante G, Batista JG, et al: Evaluation of shear bond strength of composite to porcelain according to surface treatment. Braz Dent J 2003;14:132-135

21. Matsumura H, Kawahara M, Tanaka T, et al: A new porcelain repair system with a silane coupler, ferric chloride, and adhesive opaque resin. J Dent Res 1989;68:813-818

22. Canay S, Hersek N, Ertan A: Effect of different acid treatments on a porcelain surface. J Oral Rehabil 2001;28:95-101

23. Tylka DF, Stewart GP: Comparison of acidulated phosphate fluoride gel and hydrofluoric acid etchants for porcelain-composite repair. J Prosthet Dent 1994;72:121-127

24. Wolf DM, Powers JM, O'Keefe KL: Bond strength of composite to porcelain treated with new porcelain repair agents. Dent Mater 1992;8:158-161

25. Pelógia F, Valandro LF, Brigagão V, et al: Resin microtensile bond strength to feldspathic ceramic: hydrofluoric acid etching vs tribochemical silica coating. Int J Prosthodont 2007;20:532-534

26. De Melo RM, Valandro LF, Bottino MA: Microtensile bond strength of a repair composite to leucite-reinforced feldspathic ceramic. Braz Dent J 2007;18:314-319

27. Hayakawa T, Horie K, Aida M, et al: The influence of surface conditions and silane agents on the bond of resin to dental porcelain. Dent Mater 1992;8:238-240

28. Aida M, Hayakawa T, Mizukawa K: Adhesion of composite to porcelain with various surface conditions. J Prosthet Dent 1995;73:464-470

29. Berksun S, Saglam S: Shear strength of composite bonded porcelain-to-porcelain in a new repair system. J Prosthet Dent 1994;71:423-428

30. Ozcan M, van der Sleen JM, Kurunmäki H, et al: Comparison of repair methods for ceramic-fused-to-metal crowns. J Prosthodont 2006;15:283-288

31. Alex G: Preparing porcelain surfaces for optimal bonding. Compend Contin Educ Dent 2008;29:324-335

32. Phoenix RD, Shen C: Characterization of treated porcelain surfaces via dynamic contact angle analysis. Int J Prosthodont 1995;8:187-194

33. Ozcan M: The use of chair-side silica coating for different dental applications: a clinical report. J Prosthet Dent 2002;87:469-472

34. Beck DA, Janus CE, Douglas HB: Shear bond strength of composite resin porcelain repair materials bonded to metal and porcelain. J Prosthet Dent 1990;64:529-533

35. Gregory WA, Moss SM: Effects of heterogeneous layers of composite and time on composite repair of porcelain. Oper Dent 1990;15:18-22

36. Kamada K, Yoshida K, Atsuta M: Effect of ceramic surface treatments on the bond of four resin luting agents to a ceramic material. J Prosthet Dent 1998;79:508-513

37. Matsumura H, Kato H, Atsuta M: Shear bond strength to feldspathic porcelain of two luting cements in combination with three surface treatments. J Prosthet Dent 1997;78:511-517

38. Nowlin TP, Barghi N, Norling BK: Evaluation of the bonding of three porcelain repair systems. J Prosthet Dent 1981;46:516-518

39. Chen JR, Oka K, Kawano T, et al: Carbon dioxide laser application enhances the effect of silane primer on the shear bond strength between porcelain and composite resin. Dent Mater J 2010;29:731-737

40. Shimada Y, Yamaguchi S, Tagami J: Micro-shear bond strength of dual-cured resin cement to glass ceramics. Dent Mater 2002; 18:380-388 
41. Magne P, Cascione D: Influence of post-etching cleaning and connecting porcelain on the microtensile bond strength of composite resin to feldspathic porcelain. J Prosthet Dent 2006;96:354-361

42. Saavedra G, Ariki EK, Federico CD, et al: Effect of acid neutralization and mechanical cycling on the microtensile bond strength of glass-ceramic inlays. Oper Dent 2009;34: 211-216

43. El Zohairy AA, De Gee AJ, Hassan FM, et al: The effect of adhesives with various degrees of hydrophilicity on resin ceramic bond durability. Dent Mater 2004;20:778-787

44. Kato H, Matsumura H, Atsuta M: Effect of etching and sandblasting on bond strength to sintered porcelain of unfilled resin. J Oral Rehabil 2000;27:103-110
45. Foxton RM, Nakajima M, Hiraishi N, et al: Relationship between ceramic primer and ceramic surface $\mathrm{pH}$ on the bonding of dual-cure resin cement to ceramic. Dent Mater 2003;19:779-789

46. Aboush YE: Removing saliva contamination from porcelain veneers before bonding. J Prosthet Dent 1998;80:649-653

47. Nicholls JI: Tensile bond of resin cements to porcelain veneers. J Prosthet Dent 1988;60:443-446

48. Vult von Steyern P: All-ceramic fixed partial dentures. Studies on aluminum oxide- and zirconium dioxide-based ceramic systems. Swed Dent J Suppl 2005;173:1-69

49. Kukiattrakoon B, Hengtrakool C, Kedjarune-Leggat U: The effect of acidic agents on surface ion leaching and surface characteristics of dental porcelains. J Prosthet Dent 2010;103:148-162 